\title{
Op Telic - A Field Mental Health Team In The General Support Medical Setting
}

\author{
PD McAllister, SPR Blair, S Philpott
}

\footnotetext{
Maj PD McAllister $\mathrm{BSc}$ (hons) MB BS MRCPsych RAMC Armed Forces Specialist Registrar in Psychiatry Duchess of Kent's

Psychiatric Hospital, Horne Road, Catterick Garrison, DL9 4DF Email

petemcal@doctors.org.uk
}

Capt S P R Blair

QARANC

Mental Health Nurse

RAF Wegberg

WO2 Steven Philpott QARANC

Community Mental

Health Nurse

$\mathrm{DKPH}$

\begin{abstract}
The recent conflict in the Gulf saw the large-scale deployment of Field Mental Health Teams (FMHT), in support of 1 UK Division and its constituent brigades. This article describes the activities and findings from a FMHT deployed alongside a General Support Medical Regiment covering the divisional rear area.
\end{abstract}

The rate of psychiatric casualties was much lower than anticipated, but the expected bias towards less experienced personnel and reservists was noted.

The article covers all stages of the operation from pre-deployment training, reception, staging and onward integration, operations, redeployment and homecoming, describing the core activities of the FMHT at each stage.

\section{Introduction}

Field Psychiatric teams (FPTs) were developed in the mid 1980s and exercised using simulated casualties, but were not deployed on active service until the first Gulf War (1). Bisson reports that the FPT practised within the principles of Proximity, Immediacy, Expectancy and Simplicity. He also recorded the presentation of servicemen with anxiety symptoms associated with both the NBC threat and use of the IPE, especially the Respirator.

The literature following the last Gulf war has reported that rank was the main occupational factor associated with ill-health in veterans, pre-deployment training and postdeployment training seem not to be associated with ill-health in veterans. (2). This work also described a higher risk of post-traumatic stress reaction with servicemen deployed as individual re-inforcements (IRs) in a combat role, as opposed to either Combat support or Combat services support. Their work distinguishes Combat troops, such as Infantry or Royal Armoured Corps, where personnel are more likely to be involved with combat, from the Combat support Arms, e.g. Royal Engineers and Combat Services Support Arm, e.g. the Royal Army Medical Corps. This distinction in role was recorded for all the patients seen by our team. This may be significant due to the number of IRs deployed in Op TELIC. American data $(3,4)$ note higher illness rates in reservists, although this has not been replicated in
British studies (5), this may be due to a smaller proportion of reservists being deployed i.e. $2 \%$ c.f. $20 \%$ for the US in the last Gulf conflict. Because of this our team made great efforts to brief on the potential additional needs of both IR's and reservists.

Since the last Gulf War there has been a revision of SG policy, noting the lack of evidence for critical incident stress debriefing (CISD) and as such stating that this practice was to be discontinued. Rose, Bisson and Wessely published evidence of the potential harm of CISD, as part of the Cochrane database as a systematic review in 2002 (6). Despite the absence of a clear evidence base for this practice, there is still a demand for some input post incident from within the military. The arguments for and against this use of "debriefing" are discussed by Wessely and Deahl (7). One of the Brigades within our Division, was 3 Commando Brigade, who employed the TRiM system (8).

The authors were mobilised on the 31st January 2003 to form a field mental health team, FMHT, to support the Divisional Rear Area of 1 UK Armoured Division during Op Resolute and Op TELIC. The FMHT was incorporated into 5 General Support Medical Regiment, but tasked by Medical Branch at Divisional Support Group, DSG. The role of 5 GS Med Regt is primarily the evacuation of casualties from Role 2 to Role 3. The unit's location within the Divisional Rear Area was ideal as a starting point for our provision of services to the units within the area.

The FMHT consisted of 1 Specialist Registrar and 2 Community Mental Health Nurses. The team shared three distinct roles: - Clinical, Educational and Advisory. The relative importance of these roles altered overtime, throughout the operation.

\section{Force Preparation in the UK}

As part of the formations' Op Tag training a mandatory pre-deployment stress brief was given to all troops prior to deployment. Either a unit medical officer or a community mental health nurse routinely carried this out. The aim of the presentation was to increase the troops awareness of the roles of a FMHT, and to educate them on some of the presentations of stress related illness and its immediate management in the field. This included explanation of both the PIES and 7Rs. PIES is an acronym used for Proximity (keeping the troubled soldier within his unit 
Table 1. Summary of referrals to FMHT 5 GS Med Regt during OP TELIC.

\begin{tabular}{|c|c|c|c|c|c|c|}
\hline Date & $\begin{array}{l}\text { Regular/ } \\
\text { TA }\end{array}$ & Rank & Age & Role & Diagnosis ICD-10 & Disposal \\
\hline \multicolumn{7}{|l|}{ Pre-conflict } \\
\hline 2 Mar 03 & Regular & $\mathrm{L} / \mathrm{Cpl}$ & 27 & $\begin{array}{l}\text { Combat Sp } \\
\text { Arms }\end{array}$ & $\begin{array}{l}\text { Conversion Disorder } \\
\text { F } 44\end{array}$ & $\begin{array}{l}\text { Casevaced by } \\
\text { Physicians }\end{array}$ \\
\hline 9 Mar 03 & Regular & $\mathrm{L} / \mathrm{Cpl}$ & 21 & CSS & $\begin{array}{l}\text { Recurrent Depression- in } \\
\text { remission } \\
\text { F } 33.4\end{array}$ & $\begin{array}{l}\text { Remain in } \\
\text { theatre }\end{array}$ \\
\hline 14 Mar 03 & Regular & Pte & 22 & CSS & $\begin{array}{l}\text { History of deliberate self- } \\
\text { harm } \\
\text { Z } 91.5\end{array}$ & $\begin{array}{l}\text { Admin } \\
\text { discharge QR } \\
\text { 9.381. }\end{array}$ \\
\hline 17 Mar 03 & Regular & Pte & 22 & CSS & $\begin{array}{l}\text { Concern over pregnant } \\
\text { partner-Not ill }\end{array}$ & RTU \\
\hline \multicolumn{7}{|l|}{ Conflict } \\
\hline 26 Mar 03 & TA & Spr & 29 & Combat Sp & $\begin{array}{l}\text { Not ill- unhappy in role } \\
\text { Arms }\end{array}$ & RTU \\
\hline 26 Mar 03 & Regular & Pte & 28 & CSS & Not ill- home concerns & RTU \\
\hline 3 Apr 03 & TA & $\mathrm{L} / \mathrm{Cpl}$ & 33 & CSS & Not ill- home concerns & RTU \\
\hline 4 Apr 03 & Regular & Cfn & 22 & $\begin{array}{l}\text { Combat Sp } \\
\text { Arms }\end{array}$ & $\begin{array}{l}\text { Adjustment Disorder F } \\
43.2\end{array}$ & $\begin{array}{l}\mathrm{S} 3 \mathrm{r}-6 / 12 \\
\text { repatriated }\end{array}$ \\
\hline 5 Apr 03 & Regular & Pte & 22 & CSS & $\begin{array}{l}\text { Personality disorder- } \\
\text { mixed F61.0 }\end{array}$ & $\begin{array}{l}\text { S7R } \\
\text { repatriated }\end{array}$ \\
\hline 7 Apr 03 & Regular & Sgt & 35 & Combat & Severe Depression F 32.2 & Casevac \\
\hline 7 Apr 03 & TA & $\mathrm{L} / \mathrm{Cpl}$ & 19 & $\begin{array}{l}\text { Combat Sp } \\
\text { Arms }\end{array}$ & $\begin{array}{l}\text { Adjustment Disorder } \\
\text { F } 43.2\end{array}$ & $\begin{array}{l}\text { S3r-6/12 } \\
\text { repatriated }\end{array}$ \\
\hline \multicolumn{7}{|c|}{$\begin{array}{l}\text { Post-conflict } \\
\end{array}$} \\
\hline 22 Apr 03 & TA & Cpl & 42 & CSS & $\begin{array}{l}\text { Not ill- requesting } \\
\text { repatriation }\end{array}$ & RTU \\
\hline 23 Apr 03 & TA & $\mathrm{Cpl}$ & 37 & CSS & $\begin{array}{l}\text { Not ill- requesting } \\
\text { repatriation }\end{array}$ & RTU \\
\hline 26 Apr 03 & TA & $\mathrm{L} / \mathrm{Cpl}$ & 29 & CSS & $\begin{array}{l}\text { Not ill- requesting } \\
\text { repatriation }\end{array}$ & RTU \\
\hline 7 May 03 & Regular & Pte & 19 & CSS & Not ill- anger problem & RTU \\
\hline 8 May 03 & Regular & S/Sgt & 33 & CSS & $\begin{array}{l}\text { Adjustment Disorder } \\
\text { F } 43.2\end{array}$ & $\begin{array}{l}\mathrm{S} 3 \mathrm{r}-2 / 12 \\
\text { repatriated }\end{array}$ \\
\hline
\end{tabular}

for support), Immediacy (reacting quickly to the soldiers difficulties), Expectancy (the presumption that the vast majority of acute stress reaction settle quickly with no long term sequelae) and Simplicity (the assertion that little is required beyond food, warmth, safety and suitable activity to facilitate recovery). The $7 \mathrm{Rs}$ is another Acronym to list similar support required for soldiers suffering acute stress reactions and are selfexplanatory: - Respite, Recognition of difficulties, Retention in unit, Role maintained (i.e. soldier not patient), Rest, Recounting the events and, finally Reassurance. Both PIES and the 7 Rs have been included in Educational Stress Briefings to both Commanders and Soldiers for some time.

Due to the scale of the deployment, and the large number of both individual reinforcements and reservists deployed, some members of the Armed Forces did not receive a pre-deployment stress brief. These deficiencies were rectified in theatre, through tasking from the Divisional Support Group, who detected the deficiencies within units and directed the FMHT to carry out supplementary briefings. The venues for these briefings varied from formal briefing rooms to sitting on ones webbing under the scrim with a small group of soldiers.

\section{Reception, Staging and Onward Integration Phase}

Medical Branch, through SO2 Prev Med, sought returns from individual units about the numbers of troops who still needed a predeployment stress brief. These units were then allocated to FMHTs in keeping with the Brigade and divisional boundaries i.e. the FMHT with 1 Close Support Medical Regiment were responsible for 7 Brigade units, our FMHT for the units in the Divisional Rear Area.

Throughout this phase, and the force generation phase of the campaign, the main effort of the FMHT was to give the mandatory pre-deployment stress briefs. These presentations concentrated on the recognition and management of short-lived, self-limited stress related illness. It 
emphasised the primacy of the "BuddyBuddy" support systems, followed by the additional support of the G1 chain, Unit Welfare personnel, the unit medical officers, and if necessary the FMHT. The presentation explained the importance of managing operational stress as far forward as possible, in keeping with the principles of PIES.

These in-theatre briefs responded to the needs of the troops, in particular their anxieties over the potential Biological or Chemical threat. There was very little perceived threat from a Nuclear attack. The team received a number of referrals for clinical assessments during this phase. They are summarised in Table 1, under the Preconflict heading.

The FMHT was equipped at this stage with it's own vehicle and trailer, a Global Positioning System handset and a tent which doubled as clinic and accommodation. As a divisional asset, attached to the medical regiment, the team was tasked with providing their own concept of operations, which outlined our roles and main effort for the operation. Prior to the conflict starting our main effort was to ensure that all personnel had received the mandatory briefs, as well as supporting medical officers within the Divisional Rear Area. At this stage in the operation, our scheduled box of medication had not been delivered, so the team had to relay on the emergency kit conveyed into theatre in the psychiatrist's hand luggage. Table 2 shows the scale of equipment in the psychiatric module and contrasts it with the contents of our emergency kit. The only medication used was a re-supply of a patient's anti-depressant medication, which was not included in either the emergency kit or the module; it was sourced from the soldier's unit's rear party, and sent out with personnel deployed after the initial assessment. The patient was well maintained on this therapy, was asypmtomatic and a change to an available anti-depressant may have led to a relapse and his medical evacuation from theatre.

Having independent means of travel, the FMHT maintained links with the other psychiatric assets in theatre. We visited JFLogC assets, the Psychiatric departments in the field hospitals (34,33 and 202(V)), as well as meeting with our peers from 7 Armd Bde and 16 AA Bde. We also made efforts to meet with the Regimental Medical Officers, RMOs, of the units within the Div Rear Area prior to the commencement of operations.

\section{Operations}

The transition from $\mathrm{Op}$ Resolute to $\mathrm{Op}$ TELIC commenced with the air assaults on the 19th March 2003, which were followed by the ground attack, which started with troops crossing into Iraq on the 20th March 2003. There was an initial lull in referrals, as can be seen from the dates shown in Table 1.

During this phase, Battle group recuperation was offered to the Brigades. This was a short period of time spent away from the frontline to allow the troops to recover, deal with their personal administration as well as catch up on rest. The recuperation centre worked around the clock, so that all facilities (showers, laundry, and kitchens) were available to the soldiers. The focus of the medical support to this facility was on Dental, Environmental and Mental Health. The FMHT deployed one Community Mental Health Nurse (SP) to support the troops as they rotated through the facility. SP concentrated on interfacing with Regimental Staff at the Company/Squadron Sergeant Major level, as well as liasing with the Unit RMOs as they rotated through the recuperation facility. This activity was useful for the assessment of troops, education of leaders regards stress reactions and the support of Medical Officers. Some formal referrals were received during this time either directly or through the medical section that provided primary care to the facility.

\section{Redeployment Phase}

During this time the forces were restructured, with plans for repatriation and replacement of troops. This phased repatriation caused some distress for some of the TA soldiers within our area of responsibility, who expressed dissatisfaction with their perceived stay behind role, while regular forces were sent home early to turn around to re-deploy to the Gulf on Op Telic 2 . This caused an increase in our referral rates. The details of referrals seen during this

Table 2. Equipment scale of psychiatric module compared with contents of emergency doctors kit.

\begin{tabular}{|l|lc|}
\hline Psychiatric Module 336 (Primary) & \multicolumn{3}{|l|}{ Emergency Kit (Hand luggage) } \\
\hline Diazemuls & Diazepam & $20 \times 10 \mathrm{mg} / 2 \mathrm{ml}$ vials \\
\hline Diazepam (5mg Tabs) & $\begin{array}{l}\text { Zuclopenthixol } \\
\text { Clopixol-accuphase }\end{array}$ & $5 \times 100 \mathrm{mg} / 2 \mathrm{ml}$ vials \\
\hline Droperidol & Haloperidol & $20 \times 20 \mathrm{mg} / 2 \mathrm{ml}$ vials \\
\hline $\begin{array}{l}\text { Haloperidol (Injection } \\
\text { and Tabs) }\end{array}$ & Diazepam & $20 \times 5 \mathrm{mg}$ tablets \\
\hline Citalopram & Chlordiazepoxide & $40 \times 5 \mathrm{mg}$ capsules \\
\hline $\begin{array}{l}\text { Procyclidine } \\
\text { (Injection and Tabs) }\end{array}$ & Haloperidol & $20 \times 5 \mathrm{mg}$ tablets \\
\hline
\end{tabular}


phase of Op TELIC are outlined in Table 1.

\section{Homecoming Phase}

Prior to returning home all troops were to receive a homecoming brief. The role of the brief was to make service personnel aware of the stresses associated with returning home. The presentation was provided on CD-ROM as FMed1021. This provided a challenge to the FMHT, as PowerPoint projectors were scarce, and flat clean surfaces to project on even scarcer. However we did have a copious supply of handouts, to accompany our presentations, FMed1019 and FMed1020, which summarised elements of the briefing and how to seek help once home. The serviceman's attendance at these briefs was recorded in their FMed965, as proof of their attendance at the compulsory brief prior to repatriation. A summary of the key points is included in Table 3.

To ensure that all troops received this brief, JFLogC staff delivered it at the APOD, as troops were processed onto flights out of theatre. The Divisional Support Group encouraged the area FMHTs to brief their own troops, primarily as these teams would have a more detailed knowledge of the individuals experience of the operation e.g. frequency of road traffic accidents, friendly fire incidents and contact with enemy forces. It was hoped that such material would be better received from professionals who had served alongside the units, rather than from mental health professionals from a different formation.

\section{Home Based Follow-up}

Once back in Barracks the local Departments of Community Psychiatry take responsibility for mental health issues. Due to the large size of the deployment the majority of uniformed psychiatrists, and many psychiatric nurses, from these community units, were deployed on Op TELIC. Indeed, because of the formations involved there will be continuity of care i.e. units from British Forces in Germany (BFG) were cared for by a FMHT deployed from community units in BFG. Psychiatric assets from all major Garrisons (Aldershot, Catterick, Tidworth) were represented in theatre and as such knowledge and experience of operations within the Gulf will be widespread within the community network.

Table 3. Key points from the homecoming briefs FMed 1021.

\begin{tabular}{|c|c|}
\hline SOME DO'S AND DON'TS & $\begin{array}{l}\text { - DO take time to be with your family } \\
\text { and friends. } \\
\text { DO things with your family even if you } \\
\text { do not feel like it. } \\
\text { - DO try to fit in with the routine that } \\
\text { your family has established while you } \\
\text { have been away. } \\
\text { DO look after yourself by eating and } \\
\text { sleeping well and keep up your fitness. }\end{array}$ \\
\hline SOME DO'S AND DON'TS (Continued) & $\begin{array}{l}\text { - DON'T bottle things up; try to discuss } \\
\text { concerns as they arise. } \\
\text { - DON'T try to avoid thinking and } \\
\text { talking about your tour. Your family } \\
\text { and friends will almost certainly want } \\
\text { to listen and hear all about it. } \\
\text { - DON'T isolate yourself. Try and } \\
\text { achieve a balance between being with } \\
\text { family and friends while reserving } \\
\text { some private time for yourself. } \\
\text { DON'T use alcohol in excess to cover } \\
\text { up any problems that you may } \\
\text { experience on coming home. } \\
\text { Small amounts are OK but heavy } \\
\text { drinking is very destructive to } \\
\text { readjustment. }\end{array}$ \\
\hline WHERE TO FIND HELP & $\begin{array}{l}\text { - If, despite the above advice, you } \\
\text { experience ongoing problems on } \\
\text { coming home then: } \\
\text { - Seek the advice of your friends and } \\
\text { colleagues. } \\
\text { - Seek the advice of senior colleagues. } \\
\text { - Seek the advice of your Unit Medical } \\
\text { Officer or General Practitioner. } \\
\text { Seek the advice of your Padre. }\end{array}$ \\
\hline
\end{tabular}




\section{Different Models of Mental Health Support in Op TELIC}

TRiM was used in 3 Commando Brigade, in contrast to 7 Armoured Brigade and 16 Air Assault Brigade who had FMHTs, although the 16 Air Assault Brigade FMHT had TRiM-trained personnel and utilised a system similar to TRiM. TRiM is an approach to managing psychological trauma through risk assessment. Greenberg (8) states that in global military operations conducted by the Royal Marines their psychological health needs would be best served by training Royal Marine personnel how to manage psychological trauma. As such this becomes an integral part of the planning of manpower requirements. Practitioners attend a four-day course at CTCRM, Lympstone. Although this approach is relatively recent introduction, ongoing audit will hopefully demonstrate that this is a valid method of psychological management, which can be delivered in a reliable manner. The concepts of TRiM have been published in a peer reviewed mainstream occupational health journal. (9).

In essence TRiM is a system of peer group delivered need assessment that is supported, but not delivered, by Mental Health assets. It gives commanders a structured format to follow that addresses the psychological management of potentially traumatic events. TRiM practitioners receive training in the psychological aspects of on-scene incident management, in how to conduct a brief psycho-educational lecture and in the assessment of personnel's needs in the aftermath of critical incidents. The needs assessment happens during a semi-structured meeting when the TRiM practitioner rates possibly traumatised individuals according to a tenitem risk assessment checklist. The checklist includes items such as the severity of the event, whether blame and shame is present and whether the person is accessing sufficient social support. Enquiry is also made about alcohol misuse. TRiM practitioners are specifically trained not to forcibly explore the emotional aspects of the incident which is in contrast to other post incident techniques such as CISD. The risk assessment interviews are conducted after a few days, and again after about a month has elapsed. By comparing the identified risk at the two times point practical management strategies are suggested to the identified distressed individual such as referral to the RMO, liaison with the person's commander or no action at all. TRiM practitioners are encouraged to discuss difficult cases with mental health assets, geographical constraints allowing. TRiM is not about trying to prevent post traumatic illnesses (as yet there is a lack of robust evidence which would suggest that we know how to do this) it is more about trying to ensure that the few personnel who may suffer significant prolonged post incident distress are signposted to appropriate sources of help. Ultimately this may include referral through the medical chain to field mental health teams. Primarily TRiM is about ensuring that commanders implement good personnel management techniques which do not assume that all personnel are unaffected by an event, but also avoids trying to encourage personnel to view themselves as victims.

\section{Discussion}

The authors feel that the composition of the team was appropriate. There were no issues surrounding the use of a Specialist Registrar, rather than a Consultant. Having both a nursing officer and a warrant officer, gave us excellent access to both commanders and sergeant majors. Relocating one of the mental health nurses at the recuperation centre was vital, to provide an around the clock service, with an excellent opportunity to liaise with RMOs and Commanders, as units passed through the centre.

The total number of mental health cases seen, represented only $4 \%$ of the casualties evacuated by 5 GS Medical Regiment, our parent unit. The psychiatric casualty rates that we had anticipated were between 8 and $15 \%$, depending upon the NBC threat. As anticipated both from the nature of the troops within the divisional rear area, the vast majority of our referrals involved Combat support services, those usually furthest away from actual combat. Referrals mostly came from RMOs, but interestingly the only case that warranted psychiatric casevac, was a man with severe depression, which had been picked up by his unit Padre. A number of patients were seen, temporarily downgraded and returned to their units, where repatriation could be arranged. A number of referrals were made to the team, and after an assessment was made, they were considered not to be ill. Sorts of presentation both before and during the conflict, which fell into this category were soldiers with concerns about families or partners at home, together with realistic concerns about the forthcoming conflict. These rather than being dealt with within the medical chain were recommended to be dealt with through the G1 elements at the unit, although a number were temporarily downgraded and repatriated through the administrative chain.

Once the conflict was officially over there was an increase in referrals of TA personnel who stated that they no-longer wished to be in theatre once the conflict was over, often stating that it was important for them to return for family or business reasons. Their view was compounded by seeing regular personnel being repatriated early (some for compassionate reasons or for courses, others to prepare to return on Op TELIC 2). These cases were returned to their units, for an examination of their needs for early release from their mobilisation. 
There were no presentations involving either psychotic symptoms or alcohol withdrawal at any time during the deployment.

\section{Conclusions}

It is the authors' opinion that, once again, we prepared for the worst, and thankfully our services weren't required. The numbers of psychiatric casualties to date are much lower than the levels we had predicted. We found that integration into a medical regiment, who were able to provide accommodation, transport and other support, was invaluable. The importance of dedicated transport cannot be overstated. The facility to move independently, to reach units spread throughout the Divisional Rear Area, was vital; whether it was to give briefings, liaise with RMOs and/or to see patients.

Despite our concerns about the absence of a psychiatric module throughout the deployment, we managed not to use any medication from the emergency kit.

\section{Recommendations}

1. There is a need to compare the referral rates between teams on Op Telic, along with repatriation rates. There is a need to investigate routes of repatriation through the medical chain on psychiatric grounds, when some of those returned to hospital care in the UK bypassed the in-theatre psychiatric assets, the FMHTs.

2. It would be interesting to follow-up morbidity rates by unit and contrasting regular and reservist personnel. There is likely to be screening of veterans run through Prof. Wessely's unit at King's College London, which will consider the impact of uptake of the Anthrax Immunisation upon long-term psychiatric morbidity.

3. There may be value in exercising with our attached units on a regular basis, partly to familiarise the FMHT with the kit and personnel, but also to remind everyone of our war role and how it contrasts with our peacetime occupation. This will also allow us to demonstrate why having dedicated transport and accommodation is vital.

4. The contents and availability of the psychiatric module should be re-evaluated, in the light of the experience of FMHTs in this major deployment.

\section{Acknowledgments}

The authors wish to thank Surgeon Lieutenant Commander Greenberg for his advice and support regarding this article's précis of TRiM.

\section{References}

1. Bisson J I, Military psychiatry training day: Operation Granby. Page 168.

2. Ismail $\mathrm{K}$, Blatchley $\mathrm{N}$, Hotopf $\mathrm{M}$ et al, Occupational risk factors for ill health in Gulf veterans of the United Kingdom. I Epidemiol Community Health 2000; 54:834-838.

3. Fukuda K, Nisenbaum R, Stewart G et al. Chronic multi-system illness affecting air force veterans of the Gulf War. FAMA 1998; 280:981-988.

4. The Iowa Persian Gulf Study Group. Self-reported illnesses and health status among Gulf War veterans. A population based study. $\mathscr{f} A M A 1997$; 277:238-245.

5. Unwin C, Blatchley N, Coker W et al. Health of UK servicemen who served in the Persian Gulf War. Lancet $1999 ;$ 353:169-178.

6. Rose S, Bisson J and Wessely S. Psychological debriefing for preventing post traumatic stress disorder (PTSD). Cochrane Database Syst Rev. 2002; (2): CD000560.

7. Wessely and Deahl. Debate: Psychological debriefing is a waste of time. British journal of psychiatry 2003; 183:68-74.

8. Greenberg N. A critical review of psychological debriefing: the management of psychological health after traumatic experiences. F $R$ Nav Med Serv. 2001; 87(3): 158-61.

9. N. Jones, P. Roberts, and N. Greenberg. Peer-group risk assessment: a post-traumatic management strategy for hierarchical organizations. Occup Med (Lond) 2003 53: 469-475. 